\title{
Peripheral blood miR-372 as a biomarker for ulcerative colitis via direct targeting of NLRP12
}

\author{
MENGDIE SHEN and LI'NA MENG \\ Department of Gastroenterology, The First Affiliated Hospital of Zhejiang Chinese Medical University, \\ Hangzhou, Zhejiang 310006, P.R. China
}

Received March 15, 2018; Accepted September 28, 2018

DOI: $10.3892 /$ etm.2019.7707

\begin{abstract}
The present study aimed to investigate the expression pattern and underlying mechanism of microRNA-372 (miR-372) in the progression of ulcerative colitis (UC). Reverse transcription-quantitative polymerase chain reaction was used to measure miR-372 expression levels in the blood and colonic mucosa tissue samples from patients with UC. The present study demonstrated that levels of miR-372 were significantly increased in the blood and colonic mucosa tissue samples from patients with UC compared with healthy controls. Furthermore, the level of serum miR-372 was positively correlated with the level of serum c-reactive protein. Receiver operating characteristic analysis indicated that levels of miR-372 detected in serum and tissue samples could be used to screen for patients with UC from healthy controls. These results indicated a potential role of miR-372 as a diagnostic marker and therapeutic target for patients with UC. Furthermore, a conserved miR-372 binding site in the 3'untranslated region of the NLR family pyrin domain containing 12 (NLRP12) was identified. Dual luciferase assay demonstrated that overexpression of miR-372 significantly reduced the relative luciferase activity of pmirGLO-NLRP12-3'UTR compared with control pmirGLO. In addition, western blot analysis indicated that overexpression of miR-372 significantly decreased the protein expression level of NLRP12. Therefore it was hypothesized that miR-372 may promote the progression of UC by suppressing NLRP12 protein expression and thereby inducing the excessive production of inflammatory cytokines. In conclusion, high levels of miR-372 detected in peripheral blood samples may serve a role as a potential biomarker to screen potential patients with UC from healthy controls.
\end{abstract}

Correspondence to: Dr Li'na Meng, Department of Gastroenterology, The First Affiliated Hospital of Zhejiang Chinese Medical University, 54 Youdian Road, Hangzhou, Zhejiang 310006, P.R. China

E-mail: smd7725@yeah.net

Key words: ulcerative colitis, microRNA-372, NLR family pyrin domain containing 12 , biomarker

\section{Introduction}

Inflammatory bowel disease (IBD) is a term mainly used to describe two autoimmune disorders which directly affect the gastrointestinal tract: ulcerative colitis (UC) and Crohn's disease (1). UC is a common form IBD characterized by bloody purulent stool, recurrent diarrhea and abdominal pain (2). The pathogenesis of UC is complex with numerous genetic, immune, environmental and psychological factors suggested to be involved (3). Dysregulation of immune response in the intestine and increased secretion of proinflammatoy cytokines serve a critical role in the pathogenesis of IBD (4). However, the precise etiology of IBD is unknown (4). There is an enhanced risk of developing colorectal cancer (CRC) in patients with long-term IBD and in particular, it has been suggested that patients with chronic UC carry a high risk of malignant transformation $\operatorname{IBD}(5,6)$. It is estimated that patients with UC are more than 30 times more likely to develop CRC and three times more likely to succumb to CRC compared with the general population (6).

Recent studies revealed that complex regulatory networks are involved in monitoring and responding to alterations in environmental conditions and physiological states $(4,7,8)$. Within these regulatory networks, microRNAs (miRs) can interact with downstream target genes, some of which have been linked to cancer progression (9). A recent study demonstrated that increased levels of miR-132 by aryl hydrocarbon receptor attenuate tumorigenesis associated with chronic colitis (10). Furthermore, it was revealed that miR-141 was involved in the pathogenesis of ulcerative colitis by targeting $\mathrm{C}-\mathrm{X}-\mathrm{C}$ motif chemokine ligand 5 (11). Emerging evidence has previously identified miRs that can be secreted from cells into the extracellular environment, where they are stable and resistant to degradation by RNases $(12,13)$. Circulating miRs are therefore desirable candidates as both endocrine signaling molecules and disease markers $(12,13)$.

A previous study demonstrated that high miR-372 expression is associated with synchronous liver metastasis in patients with CRC (14). In addition, serum miR-372 has been suggested to be a noninvasive biomarker for the early detection and prognosis of CRC (15). However, the involvement of circulating miR-372 in the progression of UC remains unknown. The present study demonstrated that the level of miR-372 in peripheral blood is increased in patients with UC. Furthermore, receiver operating characteristic (ROC) analysis 
demonstrated that levels of miR-372 detected in blood and tissue samples could be used to screen for patients with UC from healthy controls. These results revealed a potential role of that circulating miR-372 as a noninvasive biomarker to distinguish the progression of ulcerative colitis.

\section{Materials and methods}

Human tissue and blood samples. Colonic mucosa biopsies from the sigmoid colon of 50 patients with active UC and 50 healthy patients undergoing a screening colonoscopy were obtained from the First Affiliated Hospital of Zhejiang Chinese Medical University (Hangzhou, China) between December 2015 and June 2016 (Table I). This study was approved by the Ethics Committee at The First Affiliated Hospital of Zhejiang Chinese Medical University and written informed consent was obtained from each patient enrolled in the study. All procedures were conducted in compliance with the approved guidelines of the Ethics Committee. Pathological analysis further confirmed the diagnoses of active UC. The diagnosis of UC was confirmed by standard parameters as previously described (16). The site of disease was defined according to the Montreal classification (17). The clinical disease activity was assessed by the measurement of the Mayo score for UC. Endoscopies were performed and graded according to the ulcerative colitis endoscopic index of severity (UCEIS) scores for UC. Patients with infectious colitis and colorectal cancer were excluded. Individuals who had normal height and body mass index and no history of chronic diseases were recruited for the healthy control group. Blood samples for the measurement of high-sensitivity C-reactive protein (CRP) were taken 1 week prior to or after endoscopy. CRP was measured using a nephelometric method (18). In brief, human CRP reacted with the corresponding antisera in the liquid phase to generate antigen-antibody complexes and produce turbidity using a CRP immunoturbidimetric assay kit [DiaSys Diagnostic Systems (Shanghai) Co., Ltd., Shanghai, China] according to the manufacturer's protocol. The turbidity was associated with the antigen content and the CRP content in the sample was calculated by comparing the samples with PBS using Detection system 1 Hitachi 7600-020 automatic biochemical analyzer (Hitachi, Ltd., Tokyo, Japan). In healthy people, blood CRP levels are $<5 \mathrm{mg} / \mathrm{l}$ (18). To avoid bias, all gastroenterologists performing the endoscopies were unaware of the results from the disease activity index.

Sample acquisition and RNA isolation. From each patient, a $5 \mathrm{ml}$ aliquot of blood was collected directly into anticoagulation tubes containing ethylene diamine tetraacetic acid. Total RNA was isolated from blood or colonic mucosa tissue samples from patients with UC or healthy controls using RNAVzol LS (Vigorous Biotechnology Beijing Co., Ltd., Beijing, China), according to the manufacturer's protocol. The quantity and purity of RNA were measured using a NanoDrop spectrophotometer (ND-1000; Nanodrop Technologies; Thermo Fisher Scientific, Inc., Waltham, MA, USA).

Reverse transcription-quantitative polymerase chain reaction $(R T-q P C R)$. Total RNA $(1 \mu \mathrm{g})$ was reverse transcribed into cDNA using the Prime-Script One-Step RT-PCR kit (cat. no. C28025-032, Invitrogen; Thermo Scientific, Inc.), according to the manufacturer's protocol. qPCR was subsequently performed using SYBR ${ }^{\circledR}$ Green Supermix (Bio-Rad Laboratories, Inc., Hercules, CA, USA) using an iCycler iQ real-time PCR detection system. The following thermocycling conditions were used for the qPCR: Initial denaturation at $95^{\circ} \mathrm{C}$ for $10 \mathrm{~min} ; 50$ cycles of $95^{\circ} \mathrm{C}$ for $10 \mathrm{sec}, 55^{\circ} \mathrm{C}$ for $10 \mathrm{sec}, 72^{\circ} \mathrm{C}$ for $5 \mathrm{sec}, 99^{\circ} \mathrm{C}$ for $1 \mathrm{sec}, 59^{\circ} \mathrm{C}$ for $15 \mathrm{sec}$ and $95^{\circ} \mathrm{C}$ for $1 \mathrm{sec}$; and then cooled to $40^{\circ} \mathrm{C}$. U6 was used as an internal control. The relative mRNA expression levels were calculated with the $2^{-\Delta \Delta C q}$ method (19) and experiments were performed in triplicate. The primers used in the current study were listed as follows: miR-372-RT, 5'-GTCGTATCCAGT GCAGGGTCCGAGGTATTCGCACTGGATACGACAGAA TA-3'; U6-RT, 5'-GTCGTATCCAGTGCAGGGTCCGAG GTATTCGCACTGGATACGACAAAATG-3'; miR-372, forward 5'-GCGCCCTCAAATGTGGAGCAC-3'; U6, forward 5'-GCGCGTCGTGAAGCGTTC-3'; universal reverse primer, 5'-GTGCAGGGTCCGAGGT-3'.

Cell culture. Human colon cancer cell line HT-29 and 293T cells were obtained from the Cell Bank of Chinese Academy of Sciences (Shanghai, China) and cultured in RPMI-1640 medium (HyClone; GE healthcare, Chicago, IL, USA). HT-29 and 293T cells were seeded at a density of $1.5 \times 10^{4}$ cells $/ \mathrm{cm}^{2}$ and cultured in Dulbecco's modified Eagle's medium (Invitrogen; Thermo Fisher Scientific, Inc.) supplemented with $10 \%$ heat-inactivated fetal calf serum (Invitrogen; Thermo Fisher Scientific, Inc.), streptomycin (100 mg/ml; Thermo Fisher Scientific, Inc.), and penicillin (100 U/ml; Thermo Fisher Scientific, Inc.) and maintained at $37^{\circ} \mathrm{C}$ in a $5 \% \mathrm{CO}_{2}$ humidified incubator.

Transient transfection. HT-29 or 293 cells were seeded in the six-well plate at a density of 106 cells/well. The cells were transfected with miR-372 mimic (CCUCAAAUGUGGAGCACU AUUCU), miR-372 inhibitor (AGAATAGTGCTCCACATT TAGG) or negative control (NC, UUCUCCGAACGUGUCACG $\mathrm{U}$ ) for 48 h using Hiperfect Transfection Reagent (Qiagen GmbH, Hilden, Germany) according to the manufacturer's protocol. In brief, $12 \mu$ l Hiperfect Transfection Reagent was mixed with $100 \mu 1$ serum-free DMEM (Invitrogen; Thermo Fisher Scientific, Inc.). Additionally, $10 \mu 1 \mathrm{miR}-372 \mathrm{mimic}$, miR-372 inhibitor or $\mathrm{NC}$ was mixed with serum-free DMEM. Then, the two mixtures were mixed and incubated at room temperature for $15 \mathrm{~min}$. Then, the mixture was added to the six-well plate at a final miR concentration of $20 \mathrm{nM} /$ well. Following transfection for $48 \mathrm{~h}$, the cells were collected for subsequent experiments.

Bioinformatics analysis and dual-luciferase reporter assay. TargetScan software 7.2 (www.targetscan.org) was used to predict the putative target genes of miR-372. The 3'untranslated region (3'UTR) of NLRP12 was cloned into the pmirGLO plasmid. 293T cells were co-transfected with miR-372 mimic (or NC) and pmirGLO-NLRP12-3'UTR plasmid (or blank pmirGLO) using Vigofect transfection reagent (Vigorous Biotechnology Beijing Co., Ltd.), according to the manufacturer's protocol. In brief, 293 cells were seeded in a six-well plate at a density of $10^{6}$ cells/well. Following this, $10 \mu 1$ Vigofect transfection reagent was mixed with $100 \mu \mathrm{l}$ serum free DMEM to create a mixture. Then $10 \mu \mathrm{l}$ miR-372 mimic or NC and pmirGLO-NLRP12-3'UTR plasmid was mixed with 
Table I. Clinical characteristics of patients with UC and healthy control patients.

\begin{tabular}{lcr}
\hline Characteristics & Patients with UC & Healthy control patients \\
\hline Patients (n) & 50 & 50 \\
Males [n (\%)] & $25(50)$ & $25(50)$ \\
Age, years (mean \pm SD) & $46 \pm 15.4$ & $43 \pm 16.3$ \\
Disease duration, months [median (range)] & $65.7(25.6-173.2)$ & n/a \\
\hline
\end{tabular}

UC, ulcerative colitis; SD, standard deviation; n/a, not applicable.

A
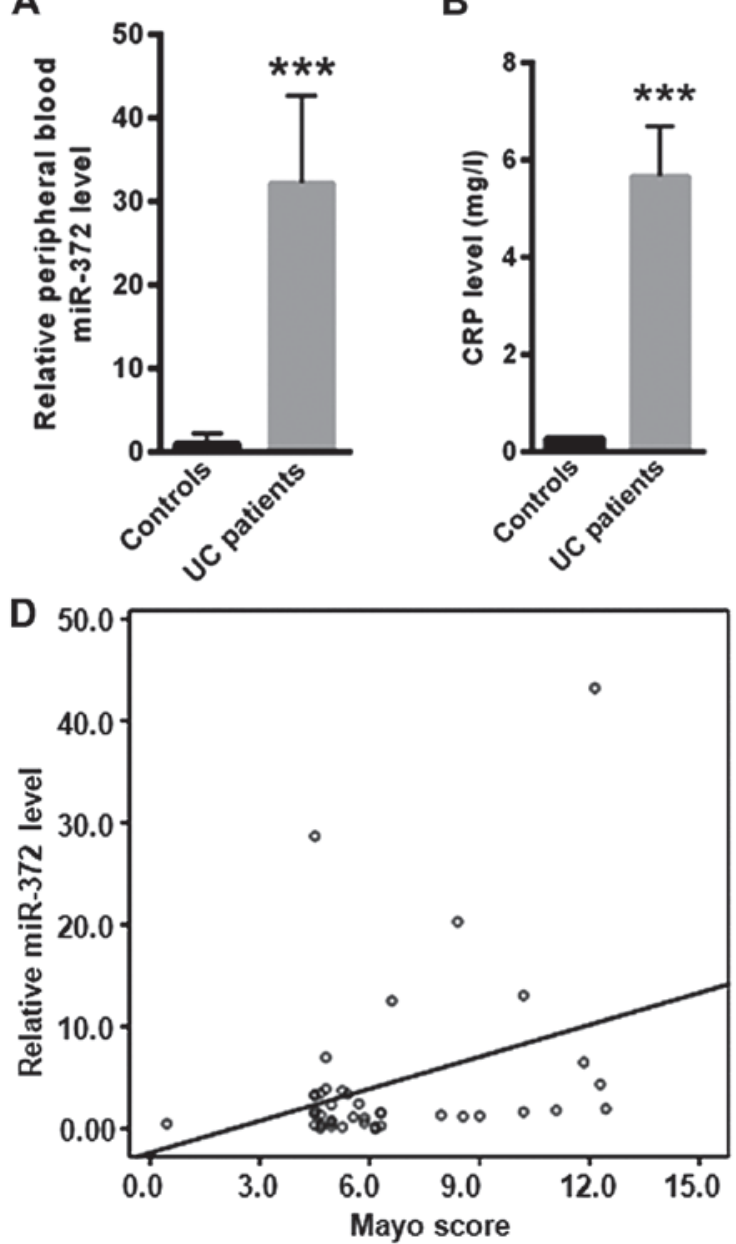

B

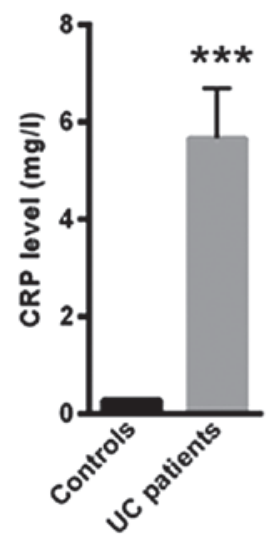

E
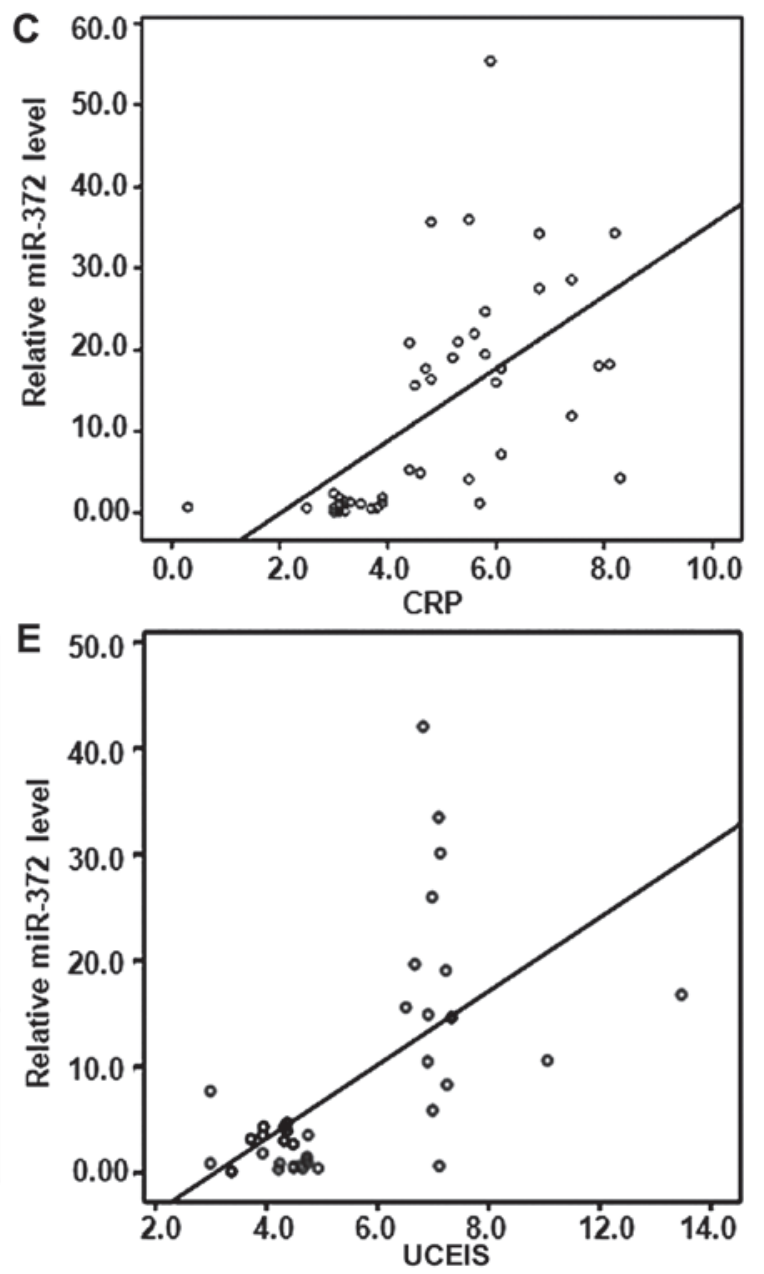

Figure 1. Peripheral blood miR-372 increases in patients with UC. (A) The expression levels of miR-372 and (B) the serum CRP were measured using blood samples from patients with UC. Pearson's correlation analysis of miR-372 with (C) serum CRP levels, (D) the Mayo score and (E) UCEIS in patients with UC. ${ }^{* * * *} \mathrm{P}<0.001$ vs. control. UC, uncreative colitis; CRP, c-reactive protein; UCEIS, ulcerative colitis endoscopic index of severity; miR, microRNA.

the aforementioned mixture at room temperature for $10 \mathrm{~min}$. The final mixture was added in the six-well plate at a final miR concentration of $20 \mathrm{nM} /$ well. After $48 \mathrm{~h}$, the luciferase activity was detected using a Dual Luciferase Reporter Assay System (Promega Corporation, Madison, WI, USA).

Western blotting. After transfection with miR-372 mimic, miR-372 inhibitor or NC for $48 \mathrm{~h}$, total proteins were isolated from HT-29 using a total protein extraction kit (Beijing Solarbio Science \& Technology Co., Ltd., Beijing, China). Then, the cell lysates were centrifuged at $12,000 \mathrm{x} \mathrm{g}$ for $30 \mathrm{~min}$ at $4^{\circ} \mathrm{C}$. To 


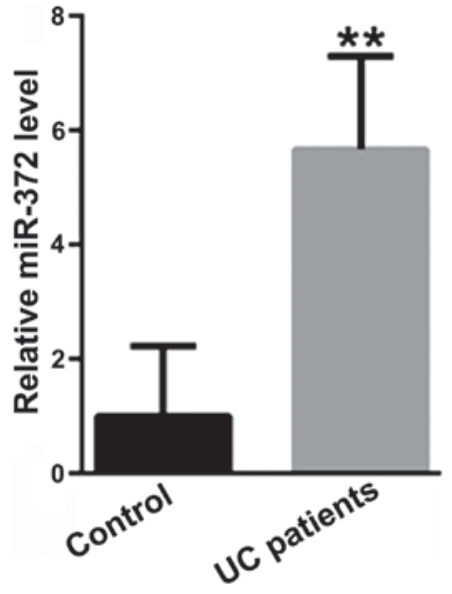

Figure 2. miR-372 is increased in UC. The mRNA expression level of miR-372 was determined by reverse transcription-quantitative polymerase chain reaction using colonic mucosa tissue samples from patients with UC. ${ }^{* * *} \mathrm{P}<0.01$ vs. control. UC, uncreative colitis; miR, microRNA.

were incubated with horseradish peroxidase-conjugated goat anti-rabbit immunoglobulin G (1:5,000; cat. no. ZB-2301; Beijing Zhongshan Golden Bridge Biotechnology Co., Beijing, China) for $2 \mathrm{~h}$ at room temperature. After washing with PBST three times ( $5 \mathrm{~min} / \mathrm{wash})$, the protein levels were determined using enhanced chemiluminescence (EMD Millipore, Billerica, MA, USA) according to the manufacturer's protocol. Signals were evaluated using a Super ECL Plus Kit (Nanjing KeyGen Biotech Co., Ltd., Nanjing, China) and quantitative analysis was performed using UVP software (UVP, LLC, Phoenix, AZ, USA). GAPDH was used as an internal control. ImageJ 1.43b software (National Institutes of Health, Bethesda, MD, USA) was used for densitometry analysis.

Statistical analysis. Data are presented as the mean \pm standard deviation. All statistical analyses were performed using SPSS software (version 20.0; IBM Corp., Armonk, NY, USA). Student's t-test was used for the comparisons of two groups. The use of miR-372 as a biomarker to distinguish disease status was determined using ROC analysis and the area under the curve was used to test discriminative ability. Spearman's correlation coefficient was used to measure the linear correlation between miR-372 expression and serum CRP levels. $\mathrm{P}<0.05$ was considered to indicate a statistically significant difference.

\section{Results}

Peripheral blood miR-372 increases in patients with $U C$. The expression level of miR-372 was significantly increased in peripheral blood samples from patients with UC compared with healthy controls $(\mathrm{P}<0.001$; Fig. $1 \mathrm{~A})$. In addition, serum CRP was significantly increased in patients with UC $(5.67 \pm 1.02 \mathrm{mg} / \mathrm{l})$ compared with healthy controls $(0.28 \pm 0.03 \mathrm{mg} / \mathrm{l} ; \mathrm{P}<0.001$; Fig. 1B). To identify the level of serum miR-372 expression with potential diagnostic value, the correlation of serum miR-372 with CRP, the Mayo score and UCEIS in patients with UC was analyzed (Fig. 1C-E). This study revealed that the level of serum miR-372 had a positive correlation with CRP $(\mathrm{r}=0.592 ; \mathrm{P}<0.001)$, the Mayo score $(\mathrm{r}=0.604 ; \mathrm{P}<0.001)$ and UCEIS $(\mathrm{r}=0.338 ; \mathrm{P}<0.001)$ in patients
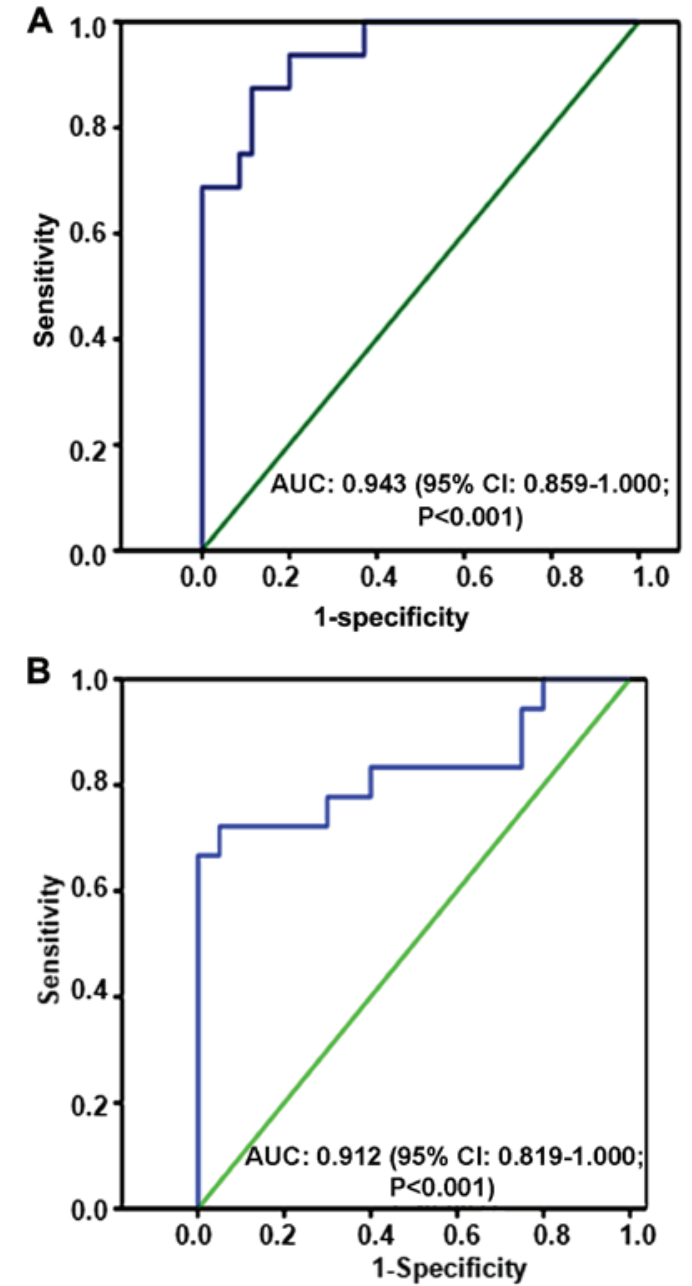

Figure 3. miR-372 as a potential biomarker for UC. (A) ROC analysis of serum miR-372. Comparison was performed across serum samples from healthy controls and patients with UC. (B) ROC analysis of miR-372 from tissue samples. Comparison was performed using tissue samples from healthy controls and colonic mucosa tissue samples from patients with UC. UC, uncreative colitis; miR, microRNA; ROC, receiver operating characteristic.

with UC. The positive correlation with these indicators of disease activity in UC suggests that the serum miR-372 level is associated with UC disease severity.

miR-372 increased in colonic mucosa tissue samples from patients with UC. The mRNA expression level of miR-372 was significantly increased in colonic mucosa tissue samples from patients with UC, compared with tissue samples from healthy controls ( $\mathrm{P}<0.01$; Fig. 2).

miR-372 as a potential biomarker for UC. To examine the feasibility of using miR-372 as a diagnostic marker, blood and tissue samples were collected from patients with UC and healthy controls. ROC analyses indicated that the serum miR-372 level had a predictive power of 0.943 (95\% confidence interval: $0.859-1.000 ; \mathrm{P}<0.001$; Fig. 3A) for distinguishing potential patients with UC from the healthy control group. Furthermore, ROC analyses indicated that the tissue miR-372 level had a predictive power of 0.912 (95\% confidence interval: 0.819-1.000; P<0.001; Fig. 3B) for distinguishing UC patients from the healthy control group. 
A

NLRP12

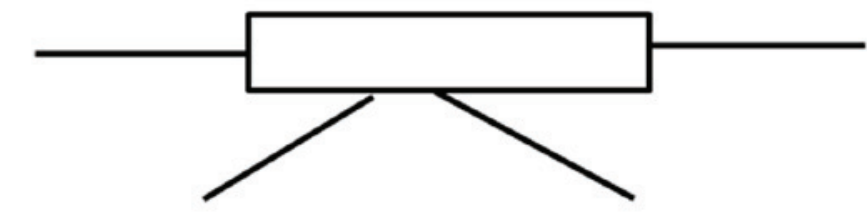

Position 196-202 of NLRP12 3'UTR 5' CAUGUAUGUAAUCCU--AGCACYUUC has-miR-372
C

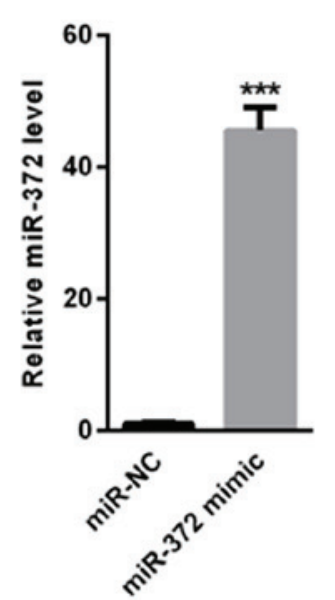

$\mathrm{E}$

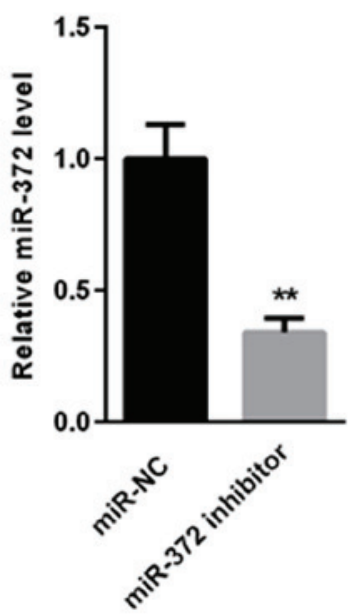

B

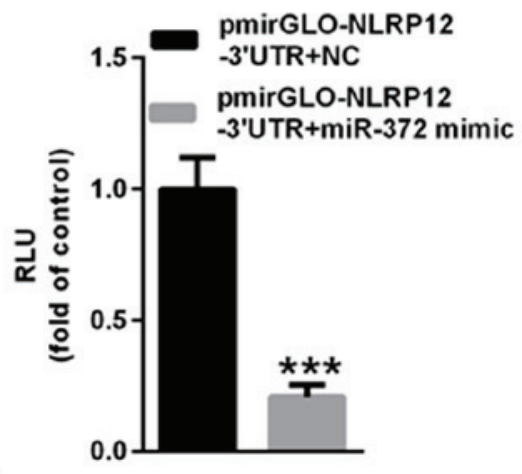

D
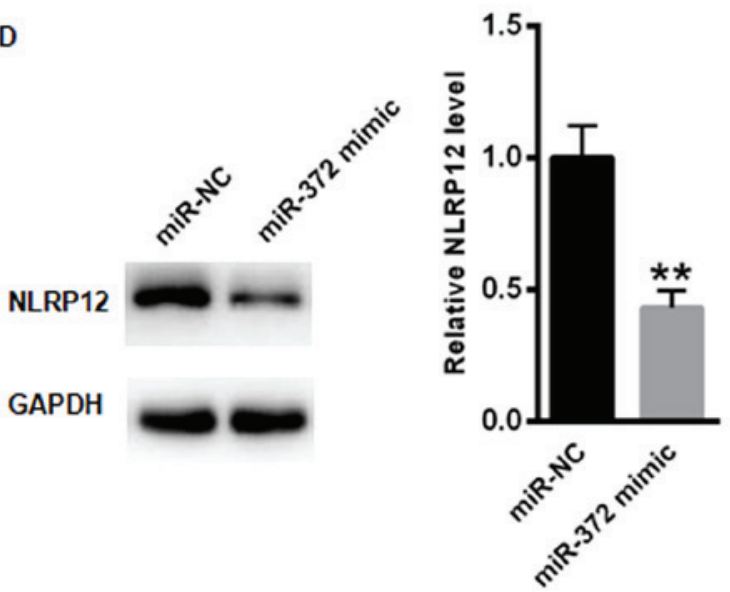

$\mathrm{F}$

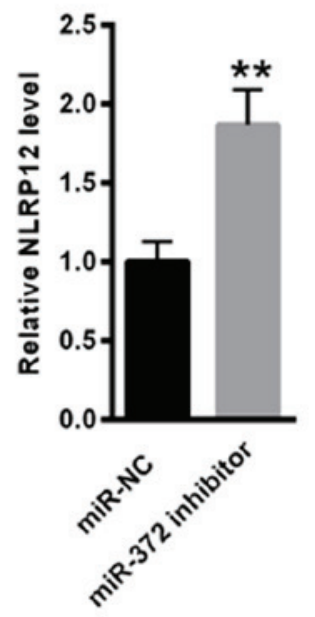

Figure 4. NLRP12 is a novel target gene of miR-372. (A) Bioinformatics analysis was used to identify a conserved miR-372 binding site in NLRP12. The structure represents the 3'UTR region of NLPR 12 and possible binding bases between miR-372 and the 3'UTR of NLPR12. (B) miR-372 mimic and pmirGLO or pmirPLO-NLRP12-3'UTR were transiently transfected into 293T cells, respectively, and the relative luciferase activity of pmirGLO-NLRP12-3'UTR was measured relative to control. miR-372 mimic and miR-NC were transiently transfected into HT-29 cells, respectively. (C) The mRNA expression level of miR-372 was detected by RT-qPCR. (D) The protein expression level of NLRP12 was determined by western blotting. miR-372 inhibitor and miR-NC were transiently transfected into HT-29 cells, respectively. (E) The mRNA expression level of miR-372 was detected by RT-qPCR. (F) The protein expression level of NLRP12 was determined by western blotting. ${ }^{* *} \mathrm{P}<0.01$ and ${ }^{* * *} \mathrm{P}<0.001$ vs. control. NLRP12, NLR family pyrin domain containing 12 ; HT-29, human colon cancer cell line; miR-NC, HT-29 cells transfected with scramble miR; miR-372 mimic, HT-29 cells transfected with miR-372 mimic; miR-NC, HT-29 cells transfected with miR-NC; miR-372 inhibitor, HT-29 cells transfected with miR-372 inhibitor; miR-372 + pmirGLO, 293T cells co-transfected with miR-372 mimic and pmirGLO; miR-372 + pmirGLO-NLRP12-3'UTR, 293T cells co-transfected with miR-372 mimic and pmirGLO-NLRP12-3'UTR; RT-qPCR, reverse transcription-quantitative polymerase chain reaction; miR, microRNA.

NLRP12 is a novel target gene of miR-372. To investigate miR-372 and its involvement in the progression of UC, TargetScan was used to identify potential targets of miR-372. TargetScan identified a conserved miR-372 binding site in the 3'UTR of NLRP12 (Fig. 4A), which was previously suggested to attenuate the progression of UC. The dual luciferase assay demonstrated that miR-372 overexpression significantly suppressed the relative luciferase activity 
of pmirGLO-NLRP12-3'UTR compared with control pmirGLO $(\mathrm{P}<0.001$; Fig. 4B). The effect of miR-153 on RUNX2 expression was examined in human colon cancer cell line HT-29 following transfection with either miR-372 mimic or miR-NC. The mRNA expression level of miR-372 significantly increased in human colon cancer cells transfected with miR-372 mimic compared with $\mathrm{NC}(\mathrm{P}<0.001$; Fig. 4C). Overexpression of miR-372 significantly decreased the protein expression level of NLRP12 (P<0.01; Fig. 4D). To further understand the effect of miR-372, HT-29 cells were transfected with either miR-372 inhibitor or miR-NC. The mRNA expression level of miR-372 significantly decreased in human colon cancer cells transfected with miR-372 inhibitor compared with $\mathrm{NC}(\mathrm{P}<0.001$; Fig. 4E). Knockdown of miR-372 significantly increased the protein expression level of NLRP12 (P<0.01; Fig. 4F).

\section{Discussion}

High sensitivity CRP is a common non-specific marker of inflammation that can be elevated in patients with active IBD $(20,21)$. However, CRP can be challenging to use as a biomarker due to its low specificity and high expression heterogeneity $(22,23)$. It is difficult to screen and monitor the progression of UC and therefore necessary to invest the use of other novel noninvasive biomarkers for patients with UC (24). Increasing evidence suggests that miRs are involved in the progression of a number of diseases, which include cancer and inflammatory diseases $(25,26)$.

The present study demonstrated that levels of miR-372 were significantly increased in the peripheral blood and colonic mucosa tissue samples from patients with UC, compared with healthy controls. Furthermore, the level of miR-372 in circulation was positively correlated with serum CRP levels. ROC analysis demonstrated that levels of miR-372 detected in both peripheral blood and colonic mucosa tissue samples could be used to screen for patients with UC from healthy controls. These results demonstrated a potential role of miR-372 as a diagnostic marker and therapeutic target for patients with UC.

The abnormal activation of inflammatory responses is a hallmark of UC $(27,28)$. The nucleotide-binding domain leucine-rich repeat proteins are important regulators of inflammatory and innate immune response, exerting pro- or anti-inflammatory functions in the development and progression of UC $(29,30)$. Studies have revealed that NLRP12 negatively regulates inflammatory signaling by suppressing both canonical and non-canonical NF- $x \mathrm{~B}$ signaling pathways, as well as regulating gut microbial communities (31-33). IBD-profiling studies indicated that NLRP12 expression is negatively correlated with active UC $(33,34)$. Furthermore, an imbalance in the intestinal microbiota, or dysbiosis serves a key role in IBD pathogenesis (35-37). There is a complex cause-effect association between intestinal microbial diversity and human disease (38). In human metabolic and inflammatory disorders including IBD, a reduction in gut microbiome richness and diversity can be used as a biomarker for disease $(39,40)$. A recent study demonstrated that NLRP12 attenuates excessive inflammatory cytokine production to limit intestinal inflammation by maintaining colonic microbial diversity and promoting protective commensal bacterial growth (33).
The current study identified NLRP12 as a novel target gene of miR-372. Dual luciferase assay demonstrated that overexpression of miR-372 significantly reduced the relative luciferase activity of pmirGLO-NLRP12-3'UTR compared with control pmirGLO. In addition, western blot analysis indicated that overexpression of miR-372 significantly decreased the protein expression level of NLRP12. Therefore, it was hypothesized that miR-372 may promote the progression of UC by suppressing NLRP12 expression, thereby inducing the production of excessive inflammatory cytokines.

In conclusion, the current study demonstrated that levels of miR-372 detected in peripheral blood were significantly increased in patients with UC compared with healthy controls. Furthermore, circulating miR-372 was positively correlated with serum CRP levels. High levels of miR-372 detected in peripheral blood samples may serve as a potential biomarker to screen patients with UC from healthy control patients.

\section{Acknowledgements}

Not applicable.

\section{Funding}

This study was supported by grants from the First Affiliated Hospital of Zhejiang Chinese Medical University (Hangzhou, China; grant no. ZJCMU-201609).

\section{Availability of data and materials}

All datasets used and/or analyzed during the current study are available from the corresponding author on reasonable request.

\section{Authors' contributions}

MS performed the experiments and analyzed the data. LM designed the study, analyzed the data and gave final approval for the version to be published.

\section{Ethical approval and consent to participate}

The current study was approved by The Ethics Committee at the First Affiliated Hospital of Zhejiang Chinese Medical University (Hangzhou, China).

\section{Patient consent for publication}

Informed consent for participation in the study or use of their tissue was obtained from all participants and all patients were consent for publication of this study.

\section{Competing interests}

The authors declare that they have no competing interests.

\section{References}

1. Bernstein CN, Blanchard JF, Kliewer E and Wajda A: Cancer risk in patients with inflammatory bowel disease: A population-based study. Cancer 91: 854-862, 2001. 
2. Haberman Y, Karns R, Dexheimer PJ, Schirmer M, Somekh J, Jurickova I, Braun T, Novak E, Bauman L, Collins MH, et al: Ulcerative colitis mucosal transcriptomes reveal mitochondriopathy and personalized mechanisms underlying disease severity and treatment response. Nat Commun 10: 38, 2019.

3. Hoving JC: Targeting IL-13 as a Host-Directed Therapy Against Ulcerative Colitis. Front Cell Infect Microbiol 8: 395, 2018.

4. Chen JH, Andrews JM, Kariyawasam V, Moran N, Gounder P, Collins G, Walsh AJ, Connor S, Lee TW, Koh CE, et al: Review article: Acute severe ulcerative colitis-evidence-based consensus statements. Aliment Pharmacol Ther 44: 127-144, 2016.

5. Akao Y, Nakagawa $Y$ and Naoe T: let-7 microRNA functions as a potential growth suppressor in human colon cancer cells. Biol Pharm Bull 29: 903-906, 2006.

6. Kanaan Z, Rai SN, Eichenberger MR, Barnes C, Dworkin AM, Weller C, Cohen E, Roberts H, Keskey B, Petras RE, et al: Differential microRNA expression tracks neoplastic progression in inflammatory bowel disease-associated colorectal cancer. Hum Mutat 33: 551-560, 2012

7. Hutchings HA, Alrubiay L, Watkins A, Cheung WY, Seagrove AC and Williams JG: Validation of the Crohn's and Ulcerative Colitis questionnaire in patients with acute severe ulcerative colitis. United European Gastroenterol J 5: 571-578, 2017.

8. Leake I: IBD: Treatment for acute severe ulcerative colitis. Nat Rev Gastroenterol Hepatol 13: 436, 2016.

9. Tili E, Michaille JJ, Piurowski V, Rigot B and Croce CM MicroRNAs in intestinal barrier function, inflammatory bowe disease and related cancers-their effects and therapeutic potentials. Curr Opin Pharmacol 37: 142-150, 2017.

10. Alzahrani AM, Hanieh H, Ibrahim HM, Mohafez O, Shehata T, Bani Ismail M and Alfwuaires M: Enhancing miR-132 expression by aryl hydrocarbon receptor attenuates tumorigenesis associated with chronic colitis. Int Immunopharmacol 52: 342-351, 2017.

11. Cai M, Chen S and $\mathrm{Hu} \mathrm{W}$ : MicroRNA-141 Is Involved in Ulcerative Colitis Pathogenesis via Aiming at CXCL5. J Interferon Cytokine Res 37: 415-420, 2017.

12. Matsuzaki J and Suzuki H: Circulating microRNAs as potential biomarkers to detect transformation of Barrett's oesophagus to oesophageal adenocarcinoma. BMJ Open Gastroenterol 4: e000160, 2017.

13. Matsuzaki $\mathbf{J}$ and Ochiya $\mathrm{T}$ : Circulating microRNAs and extracellular vesicles as potential cancer biomarkers: A systematic review. Int J Clin Oncol 22: 413-420, 2017.

14. Yamashita S, Yamamoto H, Mimori K, Nishida N, Takahashi H, Haraguchi N, Tanaka F, Shibata K, Sekimoto M, Ishii H, et al MicroRNA-372 is associated with poor prognosis in colorectal cancer. Oncology 82: 205-212, 2012.

15. Yu J, Jin L, Jiang L, Gao L, Zhou J, Hu Y, Li W, Zhi Q and Zhu X: Serum miR-372 is a diagnostic and prognostic biomarker in patients with early colorectal cancer. Anticancer Agents Med Chem 16: 424-431, 2016.

16. Conrad K, Roggenbuck D and Laass MW: Diagnosis and classification of ulcerative colitis. Autoimmun Rev 13: 463-466, 2014.

17. Kocsis D, Toth Z, Csontos AA, Miheller P, Pák P, Herszényi L, Tóth M, Tulassay $\mathrm{Z}$ and Juhász M: Prevalence of inflammatory bowel disease among coeliac disease patients in a Hungarian coeliac centre. BMC Gastroenterol 15: 141, 2015.

18. Hanafy AS, Monir MH, Abdel Malak H and Desoky Aiad M: A simple noninvasive score predicts disease activity and deep remission in ulcerative colitis. Inflamm Intest Dis 3: 16-24, 2018.

19. Livak KJ and Schmittgen TD: Analysis of relative gene expression data using real-time quantitative PCR and the 2(-Delta Delta C(T)) Method. Methods 25: 402-408, 2001.

20. Asadzadeh-Aghdaee H, Shahrokh S, Norouzinia M, Hosseini M, Keramatinia A, Jamalan M, Naghibzadeh B, Sadeghi A, Jahani Sherafat $S$ and Zali MR: Introduction of inflammatory bowel disease biomarkers panel using protein-protein interaction (PPI) network analysis. Gastroenterol Hepatol Bed Bench 9 (Suppl 1): S8-S13, 2016

21. Barnes EL and Burakoff R: New biomarkers for diagnosing inflammatory bowel disease and assessing treatment outcomes. Inflamm Bowel Dis 22: 2956-2965, 2016.

22. Pepys MB and Hirschfield GM: C-reactive protein: A critical update. J Clin Invest 111: 1805-1812, 2003.

23. Fengming $\mathrm{Y}$ and Jianbing $\mathrm{W}$ : Biomarkers of inflammatory bowel disease. Dis Markers 2014: 710915, 2014.
24. Starr AE, Deeke SA, Ning Z, Chiang CK, Zhang X, Mottawea W, Singleton R, Benchimol EI, Wen M, Mack DR and Stintzi A: Proteomic analysis of ascending colon biopsies from a paediatric inflammatory bowel disease inception cohort identifies protein biomarkers that differentiate Crohn's disease from UC. Gut 66: 1573-1583, 2017.

25. Wang H, Chao K, Ng SC, Bai AH, Yu Q, Yu J, Li M, Cui Y, Chen M, Hu JF and Zhang S: Pro-inflammatory miR-223 mediates the cross-talk between the IL23 pathway and the intestinal barrier in inflammatory bowel disease. Genome Biol 17: 58, 2016.

26. Pierdomenico M, Cesi V, Cucchiara S, Vitali R, Prete E, Costanzo M, Aloi M, Oliva S and Stronati L: NOD2 is regulated By Mir-320 in physiological conditions but this control is altered in inflamed tissues of patients with inflammatory bowel disease. Inflamm Bowel Dis 22: 315-326, 2016.

27. Krugliak Cleveland N, Rubin DT, Hart J, Weber CR, Meckel K, Tran AL, Aelvoet AS, Pan I, Gonsalves A, Gaetano JN, et al: Patients With Ulcerative Colitis and Primary Sclerosing Cholangitis Frequently Have Subclinical Inflammation in the Proximal Colon. Clin Gastroenterol Hepatol 16: 68-74, 2018.

28. Nairn RC, Savvas R, Hocking G, Kovala M and Rolland JM: Ulcerative colitis. Animal model: Immunoreactive inflammation in fetal colon implants in syngeneic adult rats. Am J Pathol 96: 647-650, 1979.

29. Al Nabhani Z, Montcuquet N, Roy M, Dussaillant M, Hugot JP and Barreau F: Complementary Roles of Nod2 in hematopoietic and nonhematopoietic cells in preventing gut barrier dysfunction dependent on MLCK Activity. Inflamm Bowel Dis 23: 1109-1119, 2017.

30. Jiang W, Wang X, Zeng B, Liu L, Tardivel A, Wei H, Han J, MacDonald HR, Tschopp J, Tian Z and Zhou R: Recognition of gut microbiota by NOD2 is essential for the homeostasis of intestinal intraepithelial lymphocytes. J Exp Med 210: 2465-2476, 2013.

31. Allen IC, Wilson JE, Schneider M, Lich JD, Roberts RA, Arthur JC, Woodford RM, Davis BK, Uronis JM, Herfarth HH, et al: NLRP12 suppresses colon inflammation and tumorigenesis through the negative regulation of noncanonical NF- $\kappa B$ signaling. Immunity 36: 742-754, 2012.

32. Zaki MH, Vogel P, Malireddi RK, Body-Malapel M, Anand PK, Bertin J, Green DR, Lamkanfi M and Kanneganti TD: The NOD-like receptor NLRP12 attenuates colon inflammation and tumorigenesis. Cancer Cell 20: 649-660, 2011.

33. Chen L, Wilson JE, Koenigsknecht MJ, Chou WC, Montgomery SA, Truax AD, Brickey WJ, Packey CD, Maharshak N, Matsushima GK, et al: NLRP12 attenuates colon inflammation by maintaining colonic microbial diversity and promoting protective commensal bacterial growth. Nat Immunol 18: 541-551, 2017.

34. Lukens JR, Gurung P, Shaw PJ, Barr MJ, Zaki MH, Brown SA, Vogel P, Chi $\mathrm{H}$ and Kanneganti TD: The NLRP12 sensor negatively regulates autoinflammatory disease by modulating interleukin-4 production in T Cells. Immunity 42: 654-664, 2015.

35. Gevers D, Kugathasan S, Denson LA, Vázquez-Baeza Y, Van Treuren W, Ren B, Schwager E, Knights D, Song SJ, Yassour M, et al: The treatment-naive microbiome in new-onset Crohn's disease. Cell Host Microbe 15: 382-392, 2014.

36. Sartor RB and Wu GD: Roles for intestinal bacteria, viruses, and fungi in pathogenesis of inflammatory bowel diseases and therapeutic approaches. Gastroenterology 152: 327-339 e324, 2017.

37. Frank DN, St Amand AL, Feldman RA, Boedeker EC, Harpaz N and Pace NR: Molecular-phylogenetic characterization of microbial community imbalances in human inflammatory bowel diseases. Proc Natl Acad Sci USA 104: 13780-13785, 2007.

38. Jacob V, Crawford C, Cohen-Mekelburg S, Viladomiu M,Putzel GG, Schneider Y, Chabouni F, O'Neil S, Bosworth B, Woo V, et al: Single delivery of high-diversity fecal microbiota preparation by colonoscopy is safe and effective in increasing microbial diversity in active ulcerative colitis. Inflamm Bowel Dis 23: 903-911, 2017.

39. Le Chatelier E, Nielsen T, Qin J, Prifti E, Hildebrand F, Falony G, Almeida M, Arumugam M, Batto JM, Kennedy S, et al: Richness of human gut microbiome correlates with metabolic markers. Nature 500: 541-546, 2013.

40. Ridaura VK, Faith JJ, Rey FE, Cheng J, Duncan AE, Kau AL, Griffin NW, Lombard V, Henrissat B, Bain JR, et al: Gut microbiota from twins discordant for obesity modulate metabolism in mice. Science 341: 1241214, 2013. 